\title{
Comparison of Liquid Chromatography-Mass/Mass Spectrometry (MS) and Gas Chromatography-MS for Quantitative Analysis of Indole-3-acetic acid and Indole-3-butyric acid from the Concentrated Liquid Fertilizer
}

\author{
Jin Hyo Kim* · Jong Min Park • Geun-Hyoung Choi • Yun-Ki Park • \\ Geon-Jae Im • Doo-Ho Kim • Oh-Kyung Kwon
}

\section{Liquid Chromatography-Mass/Mass Spectrometry (MS)와 Gas Chromatography-MS를 이용한 농축 액상 비료제품 중 Indole-3-acetic acid 및 Indole-3-butyric acid 정량분석능 비교}

김진효* · 박종민 · 최근형 · 박연기 · 임건재 · 김두호 · 권오경

Received: 4 October 2012 / Accepted: 11 December 2012 / Published Online: 31 March 2013

(C) The Korean Society for Applied Biological Chemistry 2013

\begin{abstract}
In here, we investigated the quantitative analysis method of indole-3-acetic acid (IAA) and indole-3-butyric acid (IBA) with liquid chromatography-mass/mass spectrometry (LCMS/MS) or gas chromatography-MS. Two ways of clean-up process were investigated for LC-MS/MS instrumental analysis of IAA, but both a simple dilution and hydrophile-lipophile balance (HLB) solid phase extraction (SPE) were not met the optimal recovery rates for quantitative analysis. On the other hand, the clean-up method for GC-MS was finally optimized through HLBSPE from 250-folds diluted sample and methylation with trimethylsilyl chloride in methanol for $4 \mathrm{~h}$. The limit of detection for methyl ester of IAA and IBA were both $1.4 \mathrm{mg} / \mathrm{L}$, and recovery rates showed $93-107 \%$ from the concentrated liquid fertilizer.
\end{abstract}

Keywords fertilizer - gas chromatography-mass dector · indole3-acetic acid $\cdot$ indole-3-butyric acid $\cdot$ quantitative analysis

J. H. Kim · J. M. Park · G.-H. Choi · Y.-K. Park · G.-J. Im · D.-H. Kim · O.-K. Kwon

Chemical Safety Division, National Academy of Agricultural Science, Rural Development Administration, Suwon 441-707, Republic of Korea

*Corresponding author (J. H. Kim: setup75@korea.kr)
서 론

식물에 영양을 주거나 재배를 돕기위해 토양의 물리적, 화학적 변화를 가져오게 하는 비료는 작물 재배의 필수 농자재로서, 보 통비료와 부산물비료로 구분되어 생산판매되고 있다. 이러한 비 료는 사용 목적에 맞게 다량 원소인 $\mathrm{C}, \mathrm{H}, \mathrm{O}, \mathrm{N}, \mathrm{P}, \mathrm{K}, \mathrm{Ca}$, $\mathrm{Mg}, \mathrm{S}$ 의 공급을 주목적으로 하는 제품과 $\mathrm{Fe}, \mathrm{Cl}, \mathrm{Mn}, \mathrm{Zn}, \mathrm{B}$, $\mathrm{Cu}, \mathrm{Mo}$ 와 같은 미량원소 공급을 주목적으로 하는 제품이 용도 에 따라 개발되어 사용되고 있으며 (You, 2011), 최근에는 구체 적인 목적에 맞게 사용할 수 있도록 다양한 기능성을 강조하는 비료제품 개발 시도가 잇따르고 있다. 이들 중 화학농약의 생 장조절제와 유사한 기능성이 있다고 홍보하는 비료제품이 농업 인들로부터 큰 관심을 받고 있으나 아직 그 효능이나 성분에 대해 엄밀한 검증이 이루어지지 않고 있다.

옥신은 식물 생장조절과 관련하여 100 년 이상의 연구결과로 밝혀진 식물 생장 호르몬이며, 여러 종류의 옥신 중 indole-3acetic acid (IAA)가 가장 잘 알려져 있으며, $\mathrm{IAA}$ 를 근간으로하 여 indole-3-butyric acid (IBA), naphthalene acetic acid (NAA), 2,4-dichlorophenoxy acetic acid (2,4-D), 2,4,5-trichlorophenoxy acetic acid $(2,4,5-\mathrm{T})$ 등 옥신 기능을 갖는 물질들이 개발되어 현재 사용되고 있다 (Kurepin 등, 2011; Finet과 Jaillais, 2012). 옥신은 ppm 이하의 극미량 농도에서 세포신장(Hager, 2003)과 식물굴성(Esmon 등, 2005), 관다발 발달(Davies, 2004) 및 열매 
숙성(Bottcher 등, 2010)에 관여하는 것으로 보고되었고, 미생물 에 의해 생성되는 것으로도 알려져 있다(Finet과 Jaillais, 2012). 따라서, 최근 식물생장촉진 기능성을 내세우는 비료제품 중에는 $\mathrm{IAA}$ 와 같은 옥신성분이 제조환경이나 공정에 따라 의도적 혹 은 비의도적으로 오염될 가능성이 높지만, 지금까지 고농축 비 료제품 중 미량의 옥신성분에 대한 정량 잔류 분석 연구에 대 한 보고가 없었다. IAA에 대한 정량분석은 퍼센트단위의 고농 도를 포함하는 농약제품의 품질관리를 위하여 $\mathrm{HPLC}$ 를 사용하 는 정량분석법이 공정시험법으로 개발되어 사용되고 있으나 (NAAS, 2010), 이 방법은 $\mathrm{mg} / \mathrm{L}$ 수준의 미량 분석에는 부적합 한 것으로 알려져 있다(Ali 등, 2009). 하지만, 식물체 생장점에 서 $\mathrm{mg} / \mathrm{L}$ 이하로 잔류하는 미량의 IAA에 대한 정량 분석법은 LC-MS/MS (Bottcher 등, 2010; Zhang 등, 2011)를 사용하거 나, GC-MS (Barkawi 등, 2010)를 활용하는 방법이 알려져 있 고, 이외에도 항체를 활용한 immunoaffinity assay법(Pencik 등, 2009)이 개발되는 등 생체시료에 대한 정량분석법 개발연구가 지속적으로 진행되어 왔다. 그러나, 이들 분석법들은 동물, 음 식폐기물, 광물 및 계면활성제등을 복합적으로 사용하여 제조된 고농축 액상 비료 제품에 적용하기 위한 분석법 검증이 이루어 지지 못하였고, 이로 인해 액상 비료제품 중 잔류 $\mathrm{IAA}$ 등에 대 한 잔류분석법이 마련되어 있지 않다.

질량분석기를 이용한 정량분석은 하나의 크로마토그램 내에 여러 물질이 혼합되어 있더라도 극미량의 잔류성분까지 정확하 게 분석할 수 있는 장점을 갖고 있어, 최근 정량분석에 많이 활 용되고 있다. 질량분석기를 이용한 정량분석은 여러 요인에 의 해 분석결과값이 영향을 받을 수 있으나, 이온화 단계의 ion suppression 등 matrix effect로 인한 영향이 가장 크게 고려되 고 있다. 따라서, 질량분석기를 이용한 정량분석에서 시료 전처 리 과정을 통한 간섭물질의 최소화는 매우 중요하며, 고농축 액 상비료와 같이 다량의 유기 및 무기 화합물이 포함된 시료의 분석에는 반드시 시료의 희석 혹은 정제를 통한 전처리 과정이 필요하다. 그러나, 제품 중 $\mathrm{mg} / \mathrm{L}$ 수준 이하로 잔류 가능한 성 분의 과다한 희석은 검출한계를 낮추는 방해요인이 될 수 있어, 질량분석기를 이용한 정량분석에는 최적화된 정제과정이 반드 시 요구된다. LC-MS/MS 정량 분석시험은 칼럼 정제과정을 통 해 정량 간섭물질을 제거할 수 있으며, precursor ion과 product ions을 활용하여 하나의 크로마토그램 속에 두 개 이상의 화합 물 peak이 겹쳐 있더라도 정량분석이 가능한 장점을 갖고 있다. 또한, 수용성 높고 휘발성이 낮은 IAA 및 IBA를 유도체화 할 필요가 없어 전처리 및 분석과정을 줄일 수 있는 장점도 갖고
있다. 반면, $\mathrm{IAA}$ 의 $\mathrm{GC}$ 분석에는 methylation 과정이 필요하며, 이러한 과정을 통해 분석 효율성 증진 및 시료 정제 효과를 동 시에 거둘 수 있다. Carboxylic acid의 methylation은 trimethylsilyl chloride (TMSCl) (Chen 등, 1988; Koo 등, 2008) 또는 diazomethane (Nakhooda 등, 2011; Piccoli 등, 2011) 등을 사 용한 유도체화법이 주로 사용되고 있다. 따라서, 본 연구에서는 미량요소 비료제품 중 $\mathrm{IAA}$ 및 $\mathrm{IBA}$ 의 정량 잔류분석에 적용가 능한 기기분석법을 개발하고자 $\mathrm{mg} / \mathrm{L}$ 이하의 미량 잔류분석에 활용되고 있는 $\mathrm{GC}-\mathrm{MS}$ 및 $\mathrm{LC}-\mathrm{MS} / \mathrm{MS}$ 의 적용성을 시험하고, 고농축 비료제품에 적합한 IAA 및 IBA 정량분석법을 확립하 고자 하였다.

\section{재료 및 방법}

시료 및 시약. 본 시험에 사용된 미량요소비료 제품은 시중에 유통되는 제품 중 생장조절 기능성을 강조한 제품을 구매하여 사용하였다. 시험에 사용된 methanol, acetonitrile, dichloromethane은 농약잔류분석용 등급(Merck, German)을 사용하였으며, IAA, IBA, TMSCl 및 IAA methyl ester (IAA-Me)는 AldrichSigma Co.에서 구매하여 사용하였다. 정제용 solid phase extraction (SPE)인 Florisil cartridge $(1 \mathrm{~g}, 6 \mathrm{~mL})$ 는 Applied Separations 제품 (USA)을 사용하였으며, HLB cartridge (60 $\mathrm{mg}, 3 \mathrm{~mL}$ )는 Waters 사의 OASIS 제품(Ireland)을 사용하였다. 그리고, $\mathrm{NaHCO}_{3}$ 및 $\mathrm{Na}_{2} \mathrm{SO}_{4}$ anhydrous는 $\mathrm{ACS}$ 등급(Merck)을 사용하였다.

HLB 시료정제. HLB cartridge를 $3 \mathrm{~mL}$ methanol과 $3 \mathrm{~mL}$ 증류 수로 세척한 후 $1 \mathrm{~mL}$ 의 시료를 로딩하고, 시료가 들어있는 cartridge에 methanol $3 \mathrm{~mL}$ 로 3회 용출시킨 후 용출된 용액은 무수 $\mathrm{Na}_{2} \mathrm{SO}_{4}$ 로 건조시켰다.

IAA 및 IBA methylation. HLB 정제 처리를 수행한 시료에 $\mathrm{TMSCl} 0.5 \mathrm{~mL}$ 를 넣어준 후 실온에서 4시간 교반하여 유도체 화 하였다. 유도체화된 시료용액은 감압농축 후 dichloromethane $15 \mathrm{~mL}$ 를 넣은 다음 포화 $\mathrm{NaHCO}_{3}$ 용액으로 분액정제 하였다. 유기용매층은 무수 $\mathrm{Na}_{2} \mathrm{SO}_{4}$ 를 사용하여 건조시키고 감압농축 후 dichloromethane $10 \mathrm{~mL}$ 로 재용해하고, Florisil cartridge에 로딩 한다. 시료가 들어 있는 Florisil cartridge를 dichloromethane $30 \mathrm{~mL}$ 로 용출 후 감압농축하고, methanol $2 \mathrm{~mL}$ 로 재용해하여 $\mathrm{GC}$ 기기분석에 사용하였다.

LC-MS/MS 정량분석. C18 칼럼 $(2.1 \mathrm{~mm} \times 100 \mathrm{~mm}, 3 \mathrm{~mm}$, Waters $)$

Table 1 Instrumental condition of LC-MS/MS for IAA analysis

\begin{tabular}{llll}
\hline & & \\
\hline Instrument & Agilent 1200 & HPLC & $10.0 \mu \mathrm{L}$ \\
Column & Waters $\mathrm{C}_{18}(2.1 \mathrm{~mm} \times 100 \mu \mathrm{m}, 3 \mu \mathrm{m})$ & Flow rate & $0.2 \mathrm{~mL} / \mathrm{min}$ \\
Mobile phase & A: Water with $0.01 \%$ acetic acid; B: Acetonitrile with $0.01 \%$ acetic acid & \\
Mass spectrometry (API $3200 \mathrm{Q}$ Trap) & & 31.00 \\
Ion source & ESI positive (TurbolonSpray) & Declustering potential & 9.50 \\
Ion spray voltage & $4,200 \mathrm{~V}$ & Entrance potential & 12.00 \\
MRM (amu) & $176 \rightarrow 130$ & Collision cell entrance potential & $10 \%$ \\
Temperature & $500^{\circ} \mathrm{C}$ & Collision cell exit potential & 4.00 \\
\hline
\end{tabular}


Table 2 Instrumental condition of GC-MS for methyl ester of IAA and IBA analysis.

\begin{tabular}{ll}
\hline Instrument & Agilent 6890 \\
Column & HP-5MS $(30.0 \mathrm{~m} \times 250 \mu \mathrm{m} \times 0.25 \mu \mathrm{m})$ \\
Injection vol. & $1.0 \mu \mathrm{L}$ \\
Injector Temp. & $280^{\circ} \mathrm{C}$ \\
Gas Flow $(\mathrm{He})$ & $1.0 \mathrm{~mL} / \mathrm{min}$ \\
Source Temp. & $230^{\circ} \mathrm{C}$ \\
Selected ion $(m / z)$ & 217 (quantitative for IBA), 189 (quantitative for IAA), 130 and 103 (qualitative for both IAA and IBA) \\
Oven Temp. & $70^{\circ} \mathrm{C}$ held for 2 min; $20^{\circ} \mathrm{C} / \mathrm{min}$ to $280^{\circ} \mathrm{C} ; 280^{\circ} \mathrm{C}$ held for 5 min \\
\hline
\end{tabular}

이 장착된 Agilent 1200 (Agilent, USA)와 API 3200QTrap (Applied Biosystems, USA) 질량분석기를 사용하여 IAA에 대 한 기기분석을 실시하였으며, 이동상은 $0.01 \%$ 초산이 함유된 acetonitrile과 증류수를 사용하였다. 정량분석은 multiple reaction monitoring (MRM) 조건을 $176 \rightarrow 130 \mathrm{~m} / \mathrm{z}$ 으로 설정하여 사용하 였고, IAA 표준용액 $(0.01-0.50 \mathrm{mg} / \mathrm{mL})$ 을 사용하여 검량선을 작 성하였다. 정량분석용 소프트웨어는 Analyst 1.5.1을 사용하였으 며, 자세한 LC-MS/MS 기기 설정조건은 Table 1와 같다.

GC-MS 분석. Methyl ester로 유도체화된 IAA 및 IBA에 대한 정량분석을 위한 $\mathrm{GC}$ 기기는 $\mathrm{HP}-5 \mathrm{MS}(30.0 \mathrm{~m} \times 250 \mu \mathrm{m}, 0.25$ $\mu \mathrm{m}$, Agilent) 칼럼이 장착된 Agilent 6890 (Agilent)를 사용하 였으며, IAA 분석을 위한 정량이온은 $189 \mathrm{~m} / z$, 정성이온은 103 과 $130 \mathrm{~m} / z$ 을 사용하였고, IBA 분석에는 정량이온으로 $217 \mathrm{~m} / \mathrm{z}$ 을 정성이온으로 10 과 $130 \mathrm{~m} / z$ 을 사용하였다. 구체적인 $\mathrm{GC}$ 기 기 설정조건은 Table 2와 같았다.

\section{결과 및 고찰}

LC-MS/MS 분석. IAA 및 IBA의 정량분석을 위해 유도체화 절차가 필요 없는 $\mathrm{LC}-\mathrm{MS} / \mathrm{MS}$ 분석법을 적용하여 액상 비료제 품 중 $\mathrm{mg} / \mathrm{L}$ 수준의 옥신에 대한 정량분석이 가능한 최적 조건 을 찾고자 하였다. 본 시험에서는 먼저 Zhang 등(2011)이 수행 한 LC-MS/MS법을 수정하여 별도의 정제과정 없이 희석 후 기 기분석하거나, 혹은 HLB SPE정제법을 활용하여 IAA에 대한 정량분석을 실시하였다. 시험에 사용된 IAA 표준용액은 증류수 를 사용하여 제조하였으며, 질량분석기의 $\mathrm{MRM}$ 조건을 $176 \rightarrow$ $130 \mathrm{~m} / \mathrm{z}, 176 \rightarrow 103 \mathrm{~m} / \mathrm{z}$ 그리고, $176 \rightarrow 77 \mathrm{~m} / \mathrm{z}$ 로 설정하여 최적 조건을 탐색하였고, 최종 정량분석을 위한 $\mathrm{MRM}$ 조건을 176 $\rightarrow 130 \mathrm{~m} / \mathrm{z}$ 으로 설정 하였다(Table 1). IAA 표준용액으로부터 $9.5 \mathrm{~min}$ 에 나타나는 IAA 표준물질 peak을 확인하였으며, 증류 수에 제조된 표준용액의 기기 검출한계는 $0.005 \mathrm{mg} / \mathrm{L}$ 으로 확인 되었다. 하지만 증류수가 아닌 유통 미량요소비료 제품에 대한 회수율 시험 결과, 1000 배 희석액에서 회수율이 $1 \%$ 미만 (spiking concentration $100 \mathrm{mg} / \mathrm{L}$ )으로 확인되었다. 이는 matrix effect에 의한 이온화 문제로 추정되었으며, 이를 개선하기 위해 희석 외에도 추가적인 정제과정이 필요한 것으로 판단하였다. 이에 본 시험에서는 수용액 시료에 대해 정제가 용이한 유기화 합물 정제칼럼으로 HLB cartridge를 선정하여 IAA에 대한 정 제를 시도하였다. 증류수에 녹인 IAA 표준용액에 대한 HLB cartridge의 회수율은 10 와 $0.1 \mathrm{mg} / \mathrm{L}$ 에서 $95 \%$ 이상으로 높게 나 타나 시료의 정제 가능성이 높을 것으로 기대되었으나, 액상 비
료제품에 $100 \mathrm{mg} / \mathrm{L} \mathrm{IAA}$ 를 spike하여, 증류수로 희석(100, 250, 500,1000 배)한 회수율 시험에서 matrix effect에 의한 이온화 문제 및 간섭물질 등으로 인해 LC-MS/MS를 이용한 기기분석 회수율이 $50 \%$ 미만으로 확인되었다. 결국, $\mathrm{LC}-\mathrm{MS} / \mathrm{MS}$ 를 이용 한 액상비료 제품 중 $\mathrm{mg} / \mathrm{L}$ 수준의 IAA 정량분석은 성공하지 못하였으나, 시험농도 최저 수준인 $0.1 \mathrm{mg} / \mathrm{L}$ 에서 정성분석은 가 능한 것으로 판단하였다(Fig. 1). 앞으로 $\mathrm{LC}-\mathrm{MS} / \mathrm{MS}$ 를 통한 $\mathrm{IAA}$ 및 $\mathrm{IBA}$ 의 정량분석을 위해서는 질량분석기의 분석조건을 유기산 정량분석에 유리한 ESI negative mode에서 재검토 되어 야하며, 또한, ion suppression 등 문제 개선을 위해서는 ${ }^{13} \mathrm{C}$ labelled IAA 혹은 IBA를 injection internal standard로 사용하 는등 정량 분석능 개선연구가 추가적으로 검토되어야 할 것이다. GC-MS 분석. IAA의 GC-MS 정량분석을 위해서는 carboxylic acid의 methylation이 수행되어야 하며, methylation 반응은 $\mathrm{TMSCl}$ 법 혹은 diazomethane법을 주로 사용하고 있다. TMSCl 과 methanol을 사용하는 유도체화는 $\mathrm{TMSCl}$ 을 촉매로 사용하기 때문에 관련 시약의 사용량이 적고, 유도체화 과정에 사용된 시 약들의 끓는점이 낮아 감압농축을 통해 손쉽게 제거할 수 있는 장점이 있다. 또한, 이 과정을 통한 methylation은 시료에 존재 가능한 다량의 carboxylic acid의 농도에 구애되지 않고 IAA를 포함한 대부분의 carboxylic acid에 대해 정량적인 methylation 이 가능한 반면, diazomethane을 사용하는 유도체화 반응의 경 우 carboxylic acid에 대해 당량 이상의 diazomethane 과 함께 원활한 유도체화를 위한 많은 양의 용매 사용이 요구되는 단점 을 갖고 있다. 따라서, 본 시험에서는 HLB cartridge 정제과정 과 연동하여 손쉽게 활용 가능하고, 시료 조성의 영향이 적은 $\mathrm{TMSCl}$ 를 촉매로 하는 유도체화법을 적용하여 Fig. 2와 같이 전 처리 과정을 수행하였다. 우선 유도체화된 IAA 및 IBA의 표준 용액을 이용하여 $\mathrm{GC}$ 조건설정 및 검출이온을 Table 2 와 같이 설정하였고, 이들 화합물의 머무름 시간은 각각 10.69 과 11.59 $\min$ 으로 확인하였다. 그리고 설정된 기기분석 조건에서 유도체 화 효율 및 전처리 과정의 회수율을 검증하고자 증류수에 1 $\mathrm{mg} / \mathrm{L}$ 수준의 IAA 및 IBA를 각각 spike하고, HLB 정제, methylation 및 액액분배 과정을 거친 후 최종 회수율을 조사한 결과 97 와 $98 \%$ 로 높은 회수율을 나타내었다. 또한, 비료제품 원액에 $100 \mathrm{mg} / \mathrm{L}$ 수준으로 spike한 후 증류수로 250 배 희석한 용액에서 IAA 및 IBA 회수율이 각각 93 와 $107 \%$ 로 정량분석 이 가능한 범위를 나타내었고, 액상 비료제품 중 IAA 및 IBA 에 대한 검출한계는 $1.4 \mathrm{mg} / \mathrm{L}$ 으로 확인되었다. 하지만, 본 시험 에 사용된 시료를 비료제품의 희석액이 아닌 원액을 사용하여 전처리 할 경우 $\mathrm{GC}$-inlet 및 column오염으로 인해 분석 재현성 이 좋지 않았으며, 간섭물질들의 영향으로 $\mathrm{IAA}$ 및 $\mathrm{IBA}$ 정성이 

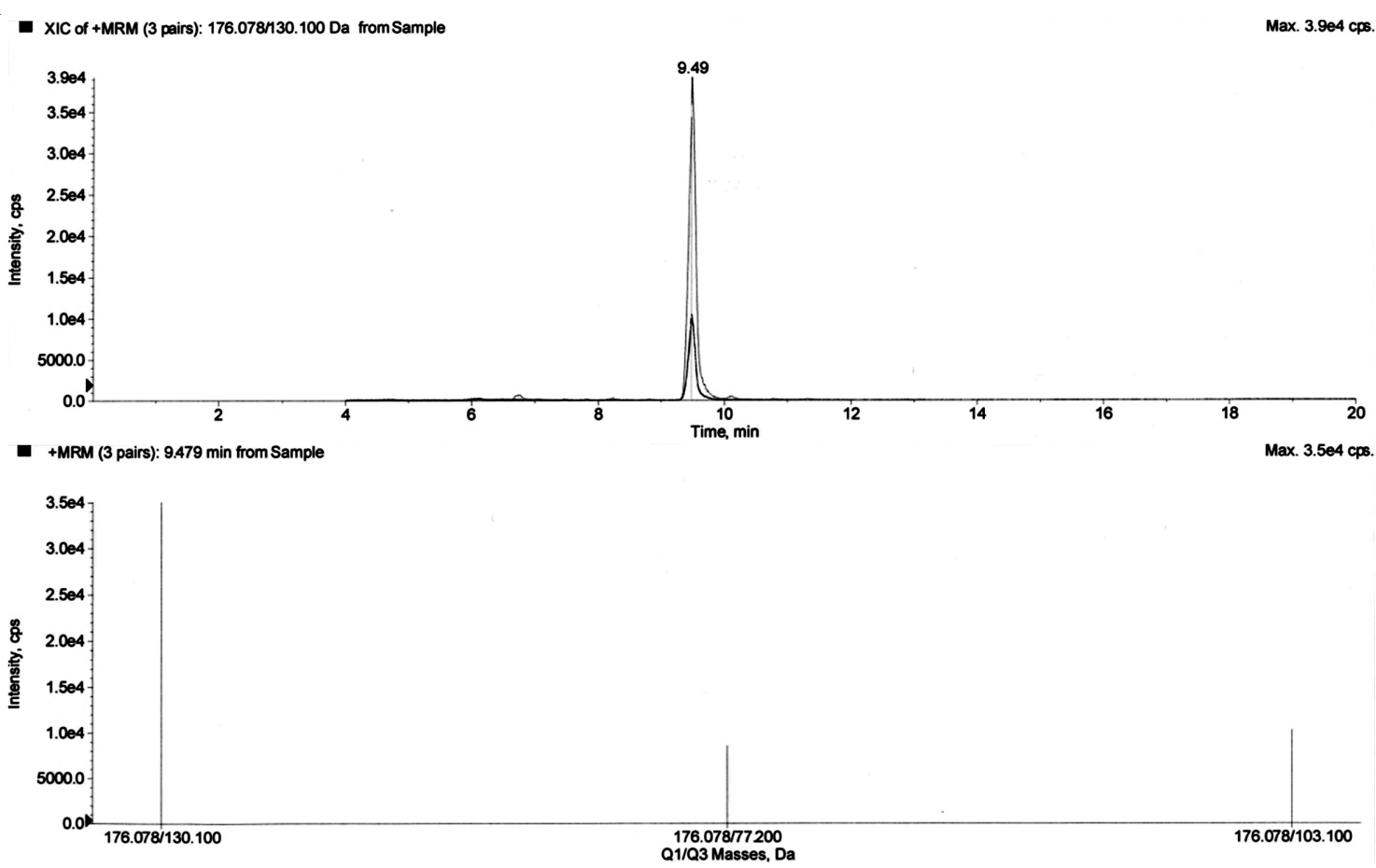

Fig. 1 LC-MS/MS chromatogram of IAA spiked sample on extracted ion chromatogram of MRM (top) and their MRM intensity (bottom) on $176.0 \rightarrow 130.1 \mathrm{~m} / \mathrm{z}, 176.0 \rightarrow 103.1 \mathrm{~m} / \mathrm{z}$ and $176.0 \rightarrow 77.2 \mathrm{~m} / \mathrm{z}$.

\begin{tabular}{|c|}
\hline Clean-up with HLB \\
\hline $\begin{array}{l}\text { - Prewashing : } 3 \mathrm{~mL} \mathrm{MeOH} \\
\text { - Conditioning : } 3 \mathrm{~mL} \text { Distilled Water } \\
\text { - Sample loading } \\
\text { - Elution : } \mathrm{MeOH}_{3} \mathrm{~mL} \times 3 \text { times } \\
\text { - Dry with } \mathrm{Na}_{2} \mathrm{SO}_{4} \text { anhydrous }\end{array}$ \\
\hline Methylation \\
\hline $\begin{array}{l}\text { - Addition of } \mathrm{TMSCl} 0.5 \mathrm{~mL} \\
\text { - Methylation for } 4 \mathrm{~h} \text { at room temperature }\end{array}$ \\
\hline Quenching and Extraction \\
\hline $\begin{array}{l}\text { - Quenching with sat. } \mathrm{NaHCO}_{3} \text { after evaporation } \\
\text { - Extraction with dichloromethane } \\
\text { - Dry with } \mathrm{Na}_{2} \mathrm{SO}_{4} \text { anhydrous } \\
\text { - Evaporation }\end{array}$ \\
\hline Clean-up with Florisil \\
\hline $\begin{array}{l}\text { - Conditioning with dichloromethane } \\
\text { - Sample Loading } \\
\text { - Elution with dichloromethane }\end{array}$ \\
\hline Evaporation and Instrumental analysis \\
\hline
\end{tabular}

Fig. 2 Clean-up procedure for quantitative analysis of IAA and IBA.

온비가 맞지 않아 정량분석이 불가능 하였다. 이로 인해 본 시 험법의 최적 희석배율은 250 배로 설정하였다.

본 시험법을 이용하여 IAA의 전구체인 트립토판 등 고농도 아미노산을 함유하여 생장조절기능성이 있다고 광고하는 제품 1 종과 액상 미량요소비료 1종에 서 $\mathrm{IAA}$ 및 $\mathrm{IBA}$ 에 대한 잔류
분석을 실시한 결과 두 시료 모두에서 $\mathrm{IBA}$ 는 검출되지 않았으 나, 기능성을 강조한 비료제품에서 IAA가 $7.7 \mathrm{mg} / \mathrm{mL}$ 검출되었 다(Fig. 3). IAA에 대한 감수성은 작물마다 다르게 나타나며, 생 장점이 아닌 부위의 IAA 함량은 $0.060 \mathrm{mg} / \mathrm{g}$ 이하, 생장점 부위 에서 $0.3-14 \mathrm{mg} / \mathrm{g}$ 범위에서 관찰되는 것으로 알려져 있다(Whang 등, 1991; Ali 등, 2009; Movac 등, 2009; Pencik 등, 2009). 따라서, IAA가 검출된 비료제품의 경우 작물에 사용할 때 최 소 500 배 희석액을 사용하도록 권장하고 있어, 해당제품을 제 조사의 권장규칙에 따라 작물에 처리할 경우 비생장점 잔류 IAA농도 수준으로 작물생육에 미치는 영향이 미약할 수 있으 나, 희석배율을 이보다 낮출 경우 작물생육에 영향을 줄 수 있 을 것으로 판단되어 사용자의 주의가 요구되었다. 이와 같이 유 통 중인 액상 비료 제품 중 옥신류가 의도적 혹은 비의도적으 로 잔류 할 수 있기 때문에, $\mathrm{mg} / \mathrm{L}$ 수준의 미량 잔류성분에 대 한 전반적인 실태 조사 연구가 필요할 것이다.

\section{초 록}

비료제품에는 의도적 혹은 비의도적으로 농약으로 등록된 indole3-acetic acid (IAA) 및 indole-3-butyric acid (IBA)성분에 대한 잔류 가능성이 꾸준히 제기되고 있으나, 생장조정제가 아닌 비 료제품에서 $\mathrm{mg} / \mathrm{L}$ 수준의 옥신류 잔류분석법이 마련되어 있지 않았다. 따라서, 본 연구에서는 생체시료에 미량 잔류하는 IAA 및 IBA 분석에 사용되어 온 liquid chromatography-mass/mass spectrometry (LC-MS/MS)와 gas chromatography-MS 기기분석 법을 활용하여 농축 액상비료제품에 적용할 수 있는지 조사하 였으며, 액상 비료제품에 적용 가능한 정밀기기 분석법을 개발 


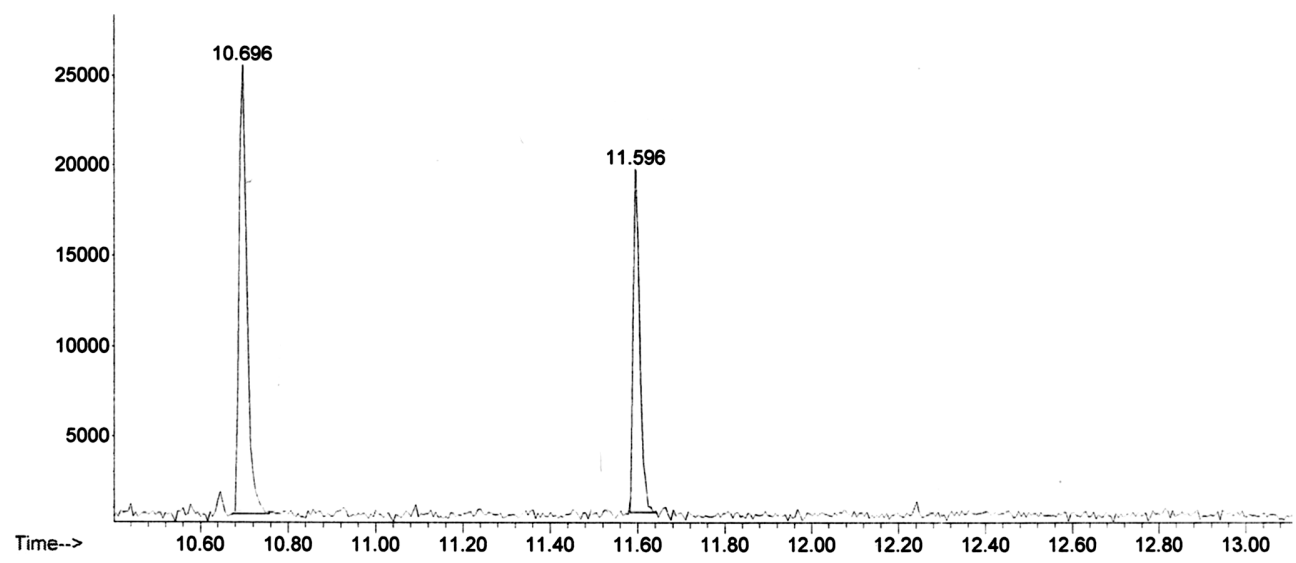

Fig. 3 GC-MS Chromatogram of methyl ester of IAA (10.696 min, SIM at 189, 130 and 103) and IBA (11.596 min, SIM at 217, 130 and 103).

하고자 하였다. 수용액 상태의 시료에서 식물 생장호르몬인 IAA 와 IBA를 가장 손쉽게 정제할 수 있는 방법으로 hydrophilelipophile balance (HLB) solid phase extraction를 활용하였으나, 제한된 조건에서 $\mathrm{LC}-\mathrm{MS} / \mathrm{MS}$ 를 통한 정량분석은 적합한 회수율 을 확보하지 못하였고, 정성분석만 가능함을 확인하였다. 반면, 비료제품 250배 희석액을 사용하여 HLB 정제, trimethylsilyl chloride을 이용한 methylation을 통한 GC-MS 분석에서는 검출 한계 $1.4 \mathrm{mg} / \mathrm{L}$ 과 $93-107 \%$ 의 회수율로 액상 비료제품에서 IAA 와 IBA 정량분석법을 확립할 수 있었다.

Keywords fertilizer - gas chromatography-mass dector · indole3 -acetic acid $\cdot$ indole-3-butyric acid $\cdot$ quantitative analysis

감사의 글 본 연구는 국립농업과학원 시험연구사업 (PJ008468)의 지원으 로 수행되었습니다.

\section{참고문헌}

Ali B, Sabri AN, Ljung K, and Hasnain S (2009) Auxin production by plant associated bacteria: impact on endogenous IAA content and growth of Triticum aestivum L. Lett Appl Microbiol 48, 542-7.

Barkawi LS, Tam Y-Y, Tillman JA, Normanly J, and Cohen JD (2010) A high-throughput method for the quantitative analysis of auxins. Nat Protoc 5, 1609-18.

Bottcher C, Keyzers RA, Boss PK, and Davies C (2010) Sequestration of auxin by the indole-3-acetic acid-amido synthetase GH3-1 in grape berry (Vitis vinifera L.) and the proposed role of auxin conjugation during ripening. J Exp Bot 61, 3615-25.

Chen KH, Miller AN, Patterson GW, and Cohen JD (1988) A rapid and simple procedure for purification of indole-3-acetic acid prior to GCSIM-MS analysis. Plant Physiol 86, 822-5.

Davies PJ (2004) Plant hormones: biosynthesis, signal transduction, action. In The Final Action of Hormones, Davies PJ (ed.), pp. 204-20. Kluwer Academic Publishers, Dordrecht, The Netherlands.

Esmon CA, Pedmale UV, and Liscum E (2005) Plant tropisms: providing the power of movement to a sessile organism. Int J Dev Biol 49, 665-74.

Finet C and Jaillais Y (2012) Auxology: When auxin meets evo-devo. Develop Biol 369, 19-31.

Hager A (2003) Role of the plasma membrane H+-ATPase in auxin-induced elongation growth: historical and new aspects. J Plant Res 116, 483-505.

Koo YJ, Yoon E, Song JT, Seo HS, Kim J-H, Lee Y-W et al. (2008) An advanced method for the determination of carboxyl methyl esterase activity using gas chromatography-chemical ionization-mass spectrometry. $J$ Chromatogr B 863, 80-7.

Kurepin L, Haslam T, Lopez-Villalobos A, Oinam G, and Yeung E (2011) Advantitious root formation in ornamental plants: II. The role of plant growth regulators. Propag Ornam Plants 11, 161-71.

Movac M, Muller A, Jarh DM, Milavec M, Duchting P, and Ravnikar M (2009) Multiple hormone analysis indicates involvement of jasmonate signalling in the early defence of potato to potato virus Y-NTN. Biologia Plantarum 53, 195-9.

NAAS (2010) Pesticide official analysis method. pp. 598-9, National Academy of Agricultural Science (NAAS), RDA, Gyeonggi, Korea.

Nakhooda M, Watt MP, and Mycock D (2011) Auxin stability and accumulation during in vitro shoot morphogenesis influences subsequent root induction and development in Eucalyptus grandis. Plant Growth Regul 65, 263-71.

Pencik A, Rolcik J, Novak O, Magnus V, Bartak P, Buchtik R et al. (2009) Isolation of novel indole-3-acetic acid conjugates by immunoaffinity extraction. Talanta 80, 651-5.

Piccoli P, Travaglia C, Cohen A, Sosa L, Cornejo P, Masuelli R et al. (2011) An endophytic bacterium isolated from roots of the halophyte Prosopis strombulifera produces $\mathrm{ABA}$, IAA, gibberellins $\mathrm{A} 1$ and $\mathrm{A} 3$ and jasmonic acid in chemically-defined culture medium. Plant Growth Regul 64, $207-10$.

Whang TE, Lim HO, and Lee JW (1991) Analysis of plant hormones by immunoassay. J Crop Sci 36, 506-12.

You OJ (2011) Fertilizer registration and quality management status, In Fast Detection Method for Formaldehyde in Wood. pp. 3-17, National Academy of Agricultural Science (NAAS), RDA, Gyeonggi, Korea.

Zhang R, Wang Y, Wang C, Wei Z, Xia D, Wang Y et al. (2011) Time-course analysis of level of indole-3-acetic acid and expression of auxinresponsive GH3 genes in Betula platyphylla. Plant Mol Biol Rep 29, 898-905. 